\title{
Effects of long-term antihypertensive treatment on brain metabolism after bilateral carotid artery occlusion in spontaneously hypertensive rats
}

\author{
K. T A M A K I, M. F U J IS H I M A, Y. NA K A T O M I, \\ T. IS H I T S U K A, J . O G A T A, A N D T . O M A E \\ From the Second Department of Internal Medicine, Faculty of Medicine, Kyushu University, \\ Fukuoka, Japan
}

SUMMARY The effects of antihypertensive treatment on brain metabolism after bilateral carotid occlusion were studied in spontaneously hypertensive rats. The results indicate that an increase in metabolites of ischaemic brain such as lactate and the lactate/pyruvate ratio after carotid occlusion in spontaneously hypertensive rats is apparently suppressed by treating hypertension. This suggests that hypertension may play an important role in susceptibility to cerebral ischaemia.

Fujishima et al. (1975) have reported that one hour after bilateral carotid artery occlusion both cerebral lactate and the lactate/pyruvate $(\mathrm{L} / \mathrm{P})$ ratio were markedly increased in spontaneously hypertensive rats (SHR), but only slightly increased in normotensive rats (NTR), indicating that SHR are susceptible to cerebral ischaemia. Such ischaemic damage to the brain has been confirmed pathologically in SHR (Ogata et al., 1976). The haemodynamic differences in the collateral circulation between SHR and NTR seem to be responsible for susceptibility to cerebral ischaemia rather than the morphological difference of cerebral vasculature (Fujishima and Omae, 1976a, b).

In the present experiment the effects of bilateral carotid occlusion on brain metabolism were studied in spontaneously hypertensive rats whose blood pressure was lowered by long-term antihypertensive treatment.

\section{Methods}

Male SHR (Okamoto and Aoki, 1963) aged 10 weeks were used. They were divided at random into two groups, one treated and the other untreated. The animals were fed a regular diet and

Address for reprint requests: Dr K. Tamaki, The Second Department of Internal Medicine, Faculty of Medicine, Kyushu University, Maidashi 3-1-1, Higashi-Ku, Fukuoka City 812, Japan.

Accepted 14 May 1979 tap water alone (untreated group), or with addition of both hydralazine $(3.5 \mathrm{mg} / \mathrm{dl})$ and guanethidine $(15 \mathrm{mg} / \mathrm{dl})$ for 10 weeks (treated group). Blood pressure was measured twice weekly by a tail-cuff method without anaesthesia. Seven Wistar normotensive rats (NTR) were used as a control group.

After 10 weeks of treatment, all animals were anaesthetised with intraperitoneally administered amylobarbitone $(100 \mathrm{mg} / \mathrm{kg}$ body weight). In each rat, one femoral artery was canulated for blood pressure recording with an electromanometer, and for anaerobic sampling of blood for $\mathrm{pH}, \mathrm{PCO}_{2}$, and $\mathrm{PO}_{2}$ determinations (IL meter Model 113). Through ventral midline cervical incisions, both common carotid arteries were exposed and separated carefully from the vagosympathetic trunks. Before ligation of the carotid arteries, $0.5 \mathrm{ml}$ of arterial blood was taken for gas analysis. After both carotid arteries were ligated simultaneously with double sutures, the animal was placed in a head-holder, and a plastic funnel was fitted into a skin incision over the skull bone for subsequent freezing of the brain tissue.

Immediately after the second arterial sample for gas analysis was taken, one hour after carotid occlusion, the head was frozen in situ by filling a plastic funnel with liquid nitrogen. The whole brain was chiselled out in the frozen state and separated grossly into the supra- and infratentorial portions. The supratentorial brain was weighed and ground in a rapid sequence, and homogenised 
after the addition of ice-cold perchloric acid. The tissue homogenate maintained at $0-4^{\circ} \mathrm{C}$ was centrifuged and neutralised with potassium hydroxide at a $\mathrm{pH}$ 4.5-5.0. Lactate, pyruvate, and adenosine triphosphate (ATP) concentrations were determined by the standard enzymatic-fluorometric methods (Bergmeyer, 1974).

During the experiment, the animals were breathing room air and their body temperature as measured in the rectum was maintained close to $37^{\circ} \mathrm{C}$. Immediately after killing, the heart was removed and weighed for relative heart weight or percentile ratio of heart/body weight.

We discarded the results of those animals whose systolic blood pressure did not exceed $180 \mathrm{mmHg}$ in untreated SHR or did not fall below that level in the treated SHR during an observation period of 10 weeks, or whose arterial acid-base parameters did not show the normal range of values during the experiment. Nine untreated and nine treated SHR were finally available for analysis in the present study, which was of five paired siblings.

\section{Results}

Average values for systolic blood pressure (SBP) at age 10 weeks before antihypertensive treatment were $177 \pm 4 \mathrm{mmHg}$ (SEM) in the untreated SHR group and $185 \pm 6 \mathrm{mmHg}$ in the treated group, and the difference was not significant. During the next 10 weeks, SBP in the untreated group rose progressively and reached a mean value of $222 \pm$ $4 \mathrm{mmHg}$. In treated animals SBP fell markedly for the first two weeks, and then showed a gradual rise but below the initial level $(174 \pm 4 \mathrm{mmHg})$. The difference in the final SBP level between the

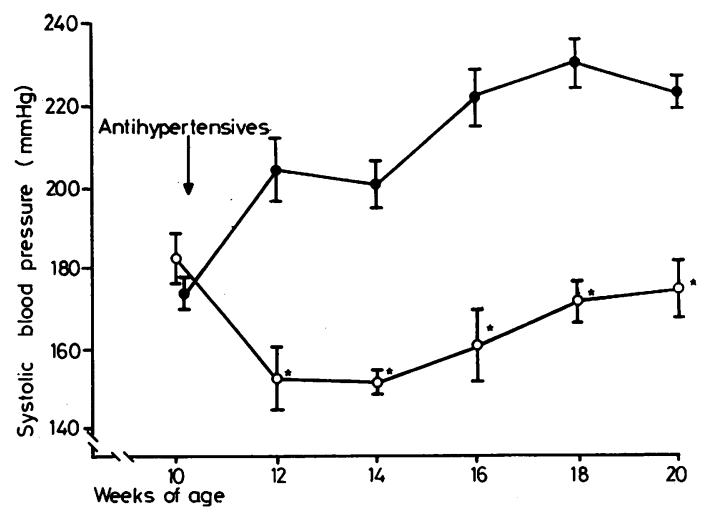

Fig. 1 Systolic blood pressure in untreated (O) and treated (O) $S H R$. Vertical bar denotes $S E M$, $* P<0.001$. two groups was highly significant (Fig. 1). On the other hand, SBP in control normotensive rats was $130 \pm 6 \mathrm{mmHg}$, significantly lower than in SHR.

Although there was no difference in body weight, average value for relative heart weight ratio was $0.44 \pm 0.01 \%$ in untreated SHR and $0.41 \pm 0.01 \%$ in treated ones, a statistically significant difference $(P<0.05)$. This indicates that antihypertensive treatment may prevent hypertensionrelated cardiac hypertrophy.

In the untreated SHR group, mean arterial blood pressure (MAP), directly measured through the canulated femoral artery, averaged $189 \mathrm{mmHg}$ before carotid occlusion, and it rose abruptly after occlusion, with a restoration to the initial level at one hour after occlusion. The MAP in the treated SHR group was also raised and remained above the initial level $(153 \mathrm{mmHg})$ one hour after occlusion, while the control group showed no remarkable change in MAP $(119 \mathrm{mmHg})$.

As shown in Table 1 , arterial $\mathrm{PCO}_{2}$ did not differ between untreated and treated SHR before carotid occlusion. After occlusion, there was at significant reduction of $\mathrm{PCO}_{2}$ by $13.1 \pm 1.6 \mathrm{mmHg}$ in untreated and $4.6 \pm 1.1 \mathrm{mmHg}$ in treated SHR with a reciprocal rise in arterial $\mathrm{pH}$ in each group. On the other hand, arterial $\mathrm{PCO}_{2}$ in NTR remained unchanged. Arterial $\mathrm{PO}_{2}$ did not differ between untreated and treated SHR before and after carotid occlusion.

Mean values for supratentorial metabolites are summarised in Table 2. After carotid occlusion, cerebral lactate in treated SHR averaged 6.82 $\mathrm{mmol} / \mathrm{kg}$ which was significantly lower $(\mathrm{P}<0.001)$ than the level of $14.42 \mathrm{mmol} / \mathrm{kg}$ found in untreated animals (Fig. 2). Levels of ATP in treated SHR were slightly but not significantly higher than in untreated ones.

Figure 3 illustrates a linear correlation between MAP before and cerebral lactate after carotid occlusion in the individual animal. A similar correlation was also obtained between MAP and L/P ratio $(r=0.63, \mathrm{P}<0.01)$. In contrast, there was an inverse relationship between cerebral lactate and arterial $\mathrm{PCO}_{2}$. The animals with higher lactate levels tended to have a reduced $\mathrm{PCO}_{2}$ after carotid occlusion, suggesting that cerebral ischaemia caused hyperventilation.

\section{Discussion}

It takes approximately two months to develop a sustained hypertension in spontaneously hypertensive rats (Okamoto and Aoki, 1963), and hypertension is usually associated with an increase in 
Table 1 Arterial acid-base balance before and one hour after bilateral carotid occlusion

\begin{tabular}{|c|c|c|c|c|c|c|}
\hline \multirow[t]{2}{*}{ Group } & \multicolumn{2}{|l|}{$p H$} & \multicolumn{2}{|c|}{$\mathrm{PCO}_{2}(\mathrm{mmHg})$} & \multicolumn{2}{|c|}{$\mathrm{PO}_{2}(\mathrm{mmHg})$} \\
\hline & Before & After & Before & After & Before & After \\
\hline $\begin{array}{l}\text { Untreated } \\
\text { SHR }(N=9)\end{array}$ & $7.397 \pm 0.008$ & $7.499 \pm 0.019$ & $32.6 \pm 1.1$ & $22.5 \pm 1.3$ & $81.8 \pm 2.8$ & $90.2 \pm 3.6$ \\
\hline $\begin{array}{l}\text { Treated SHR } \\
(\mathrm{N}=9)\end{array}$ & $7.425 \pm 0.010$ & $7.458 \pm 0.014$ & $33.2 \pm 1.2$ & $28.6 \pm 1.1$ & $85.1 \pm 3.6$ & $89.2 \pm 3.9$ \\
\hline $\begin{array}{l}\text { NTR } \\
(\mathrm{N}=7)\end{array}$ & $7.392 \pm 0.011$ & $7.431 \pm 0.017$ & $40.9 \pm 1.5$ & $38.6 \pm 1.6$ & $103.0 \pm 2.9$ & $95.9 \pm 3.8$ \\
\hline
\end{tabular}

Values are mean $\pm \mathrm{SEM}$

Table 2 Supratentorial brain metabolites one hour after bilateral carotid occlusion in untreated SHR, treated $S H R$, and NTR

\begin{tabular}{|c|c|c|c|c|c|c|}
\hline Group & Lactate $(\mathrm{mmol} / \mathrm{kg})$ & Significance & $L / P$ ratio & Significance & $A T P(\mathrm{mmol} / \mathrm{kg})$ & Significance \\
\hline $\begin{array}{l}\text { Untreated } \\
\text { SHR }(\mathbf{N}=9)\end{array}$ & $14.42 \pm 1.62$ & $P<0.001$ & $101.5 \pm 14.5$ & $\mathrm{P}<0.02$ & $1.14 \pm 0.60$ & NS \\
\hline $\begin{array}{l}\text { Treated SHR } \\
(\mathrm{N}=9)\end{array}$ & $6.82 \pm 0.93$ & $\mathrm{P}<0.01$ & $51.3 \pm 11.6$ & NS & $1.51 \pm 0.15$ & $P<0.001$ \\
\hline $\begin{array}{l}\text { NTR } \\
(\mathbf{N}=7)\end{array}$ & $3.21 \pm 0.21$ & & $25.1 \pm 2.4$ & & $2.88 \pm 0.10$ & \\
\hline
\end{tabular}

Values are mean $\pm S E M$

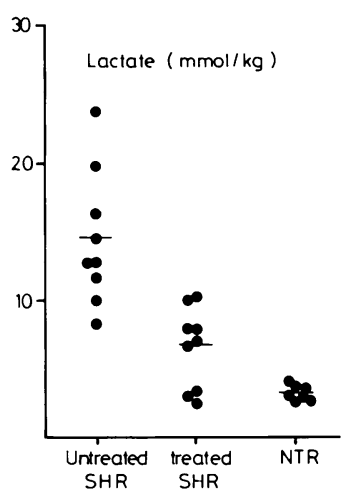

Fig. 2 Supratentorial lactate and lactate/pyruvate ratio one hour after bilateral carotid artery occlusion in untreated $S H R$, treated $S H R$, and NTR.

the peripheral vascular resistance (Finch and Haeusler, 1974; Lais et al., 1974; Iriuchijima et al., 1975). Folkow et al. (1970a, b) have reported that the increased vascular resistance is caused by an adaptive hypertrophy of the vascular wall exposed to the increased strain of the intraluminal blood pressure.

Although the distribution of cerebral vasculature, particularly of the circle of Willis, is essentially the same, the diameter of cerebral arteries is somewhat smaller in SHR than NTR but the hypertension-related morphological

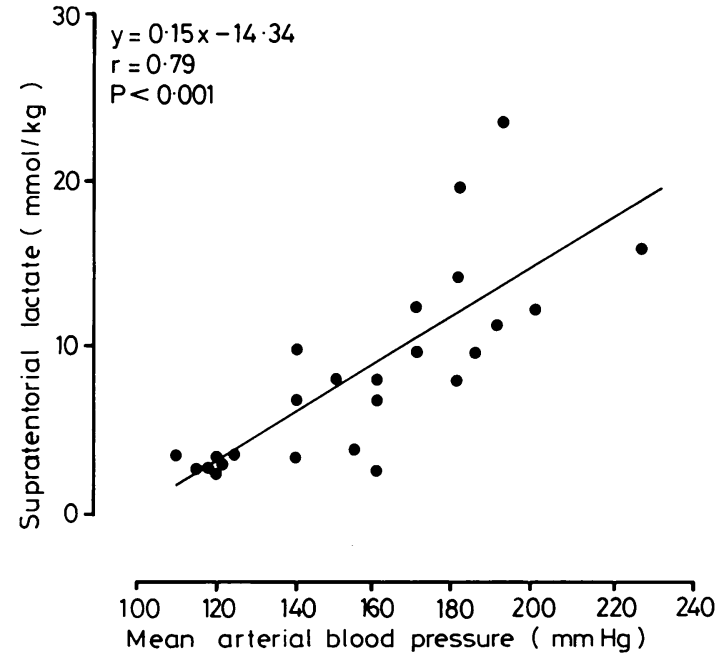

Fig. 3 Relationship between supratentorial lactate and mean arterial pressure $(M A P)$ before ligation in untreated $S H R$, treated $S H R$, and NTR.

changes of vessel walls such as angionecrosis are not evident in SHR (Ogata et al., 1976). On the contrary, Amano (1977) has observed the arterial changes designated as hyalinosis in SHR over the age of 20 weeks, but not in either younger SHR or NTR.

By lowering the blood pressure in hypertension, 
a high vascular resistance is reduced in either humans (Sivertsson and Hansson, 1976) or laboratory animals (Folkow et al., 1971a, b; Weiss, 1974). Folkow (1971b) demonstrated that a rapid and considerable regression of the hypertrophic vascular adaptation to hypertension takes place when the pressure load is kept reduced to a normal level for only eight weeks or less. In the present study, antihypertensive treatment for 10 weeks achieved a significant reduction of the blood pressure but did not restore it to the normotensive level.

An increase in supratentorial lactate and $L / P$ ratio after carotid occlusion was markedly suppressed in SHR by long-term treatment of hypertension. The differences in ischaemic metabolites after carotid occlusion among three groupstreated and untreated SHR and NTR-seem to be related to the level of blood pressure. Therefore, a moderate increase in both cerebral lactate and $\mathrm{L} / \mathrm{P}$ ratio even in treated SHR is probably the result of an insufficient lowering of the blood pressure despite 10 weeks of treatment.

The lower limit of cerebral autoregulation is shifted to a higher level in SHR than NTR (Fujishima and Omae, 1976a). Meanwhile, carotid back pressure as an indicator of the cerebral perfusion pressure is greatly lowered after bilateral carotid occlusion in SHR but not in NTR (Fujishima and Omae, 1976b). These findings in SHR seem to be responsible for an increased vascular resistance of the brain, resulting in an insufficient perfusion through the collateral circulation after carotid occlusion. When a high blood pressure is reduced by antihypertensive treatment for a certain period of time, hypertrophic vascular changes might regress, with restoration of cerebral vascular resistance. Cerebral autoregulation is also returned towards or close to the normal level as demonstrated in hypertensive patients (Strandgaard, 1976), and then collateral channels might function more effectively. Therefore, cerebral perfusion might be kept reasonably good even after bilateral carotid occlusion in those rats with a long-term administration of antihypertensive agents, possibly lowering the susceptibility to cerebral ischaemia.

We would like to thank Miss Mayumi Taki and Miss Makiko Yamaguchi for technical assistance, and Miss Junko Hirakawa for preparing this manuscript. Hydralazine (Apresoline) and guanethidine (Ismelin) used in this study were kindly provided by Ciba-Geigy (Japan), Ltd. The work was supported in part by Grant No. 244045 for scientific research from the Japanese Ministry of Education.

\section{References}

Amano, S. (1977). Vascular changes in the brain of spontaneously hypertensive rats: hyaline and fibrinoid degeneration. Journal of Pathology, 121, 119 128.

Bergmeyer, H. U. (1974). Methods of Enzymatic Analysis, second English edition. Academic Press: New York.

Finch, L., and Haeusler, G. (1974). Vascular resistance and reactivity in hypertensive rats. Blood Vessels, 11, 145-158.

Folkow, B., Hallbäck, M., Lundgren, Y., and Weiss, L. (1970a). Structurally based increase of flow resistance in spontaneously hypertensive rats. Acta Physiologica Scandinavica, 79, 373-378.

Folkow, B., Hallbäck, M., Lundgren, Y., and Weiss, L. (1970b). Background of increased flow resistance and vascular reactivity in spontaneously hypertensive rats. Acta Physiologica Scandinavica, 80, 93-106.

Folkow, B., Guarevich, M., Hallbäck, M., Lundgren, Y., and Weiss, L. (1971a). The hemodynamic consequences of regional hypotension in spontaneously hypertensive and normotensive rats. Acta Physiologica Scandinavica, 83, 532-541.

Folkow, B., Hallbäck, M., Lundgren, Y., and Weiss, L. (1971b). The effect of intense treatment with hypotensive drugs on structural design of the resistance vessels in spontaneously hypertensive rats. Acta Physiologica Scandinavica, 83, 280-282.

Fujishima, M., and Omae, T. (1976a). Lower limit of cerebral autoregulation in normotensive and spontaneously hypertensive rats. Experientia, 32, 10211022.

Fujishima, M., and Omae, T. (1976b). Carotid back pressure and spontaneously hypertensive rats. $E x-$ perientia, 32, 1022-1023.

Fujishima, M., Sugi, T., Morotomi, Y., and Omae, T. (1975). Effects of bilateral carotid artery ligation on brain lactate and pyruvate concentrations in normotensive and spontaneously hypertensive rats. Stroke, 6, 62-66.

Iriuchijima, J., Numao, Y., and Suga, H. (1975). Effect of increasing age on hemodynamics of spontaneously hypertensive rats. Japanese Heart Journal, 16, 257-264.

Lais, T. L., Shaeffer, A. R., and Brody, J. M. (1974). Neurogenic and humoral factors controlling vascular resistance in the spontaneously hypertensive rat. Circulation Research, 35, 764-774.

Okamoto, K., and Aoki, K. (1963). Development of a strain of SHR. Japanese Circulation Journal, 27, 282-293.

Ogata, J., Fujishima, M., Morotomi, Y., and Omae, T. (1976). Cerebral infarction following bilateral carotid ligation in normotensive and spontaneously hypertensive rats. Stroke, 6, 62-66.

Sivertsson, R., and Hansson, L. (1976). Effects of blood pressure reduction on the structural vascular abnormality in skin and muscle vascular beds in human essential hypertension. Clinical Science and Molecular Medicine, 51, 77-79. 
Strandgaard, S. (1976). Autoregulation of cerebral blood flow in hypertensive patients: the modifying influence of prolonged antihypertensive treatment on the tolerance to acute, drug-induced hypotension. Circulation, 53, 720-727.
Weiss, L. (1974). Long term treatment with antihypertensive drugs in spontaneously hypertensive rats (SHR). Effects on blood pressure, survival rate and cardiovascular design. Acta Physiologica Scandinavica, 91, 393-408. 